\title{
Reclassification of College and University Libraries'
}

Miss MacPherson, assistant professor, School of Library Service, Columbia University, investigated five different sources of information in order to throw new light on the problem of reclassification. The most authoritative and up-to-date facts were obtained from questions sent to twenty libraries that have experienced either whole or partial reclassification of their collections.

$\mathrm{T}$ HE TERM "reclassification," as applied to library collections, is sometimes employed to describe the process of revising, and perhaps expanding, an existing system of classification, and of fitting the book collection into the renovated system. "Reclassification" is used here in its more exact sense-to describe the process of changing a collection from one classification system to an entirely different scheme.

\section{Sources of Information}

The present discussion of the subject is based on information gleaned from the following sources: (I) my past experience as a practical classifier; (2) talks with administrators and classifiers in various types of libraries; (3) personal observation of classification conditions in libraries in different parts of the United States and Europe; (4) printed material relating to reclassification; (5) returns from a

1 Summary of a paper presented at the Fastern College Librarians' Conference, held at Columbia University Library, Nov. 25. I939. set of questions sent out on October 25, 1939, to the administrators of twenty American college and university libraries.

\section{Example Drawn from Experience}

In order to have some specific problem to illustrate the practical classification end, I have decided to recount the trials of reclassifying a small group of books in the field of business. The setting was in Columbia University Library about the year $192 \mathrm{I}$, the number of books involved was 4000 , and the facts have been verified recently by reference to rough notes that were taken at that period. There is some justification for criticizing an attempt to draw facts from a case that happened so long ago, and where the circumstances were undoubtedly peculiar to the individual library involved. I might say, however, that in the light of my later contacts with reclassification, history has seemed to repeat itself and local circumstances in libraries have never failed to present unusual angles.

The task was to transfer about 4000 volumes from the 650 class of the Decimal Classification to the places provided for this subject in a new, special scheme of classification which had just been worked out for the School of Business Library. New accessions were classified at once according to the special system, but the older volumes had to be attended to in the spare 
time of the cataloger and her one professional assistant.

The handling of 4000 volumes would, on the surface, seem a small task, especially since there were many duplicate copies of certain titles. Yet the reclassification involved the removal, frequent remaking, and the refiling of 8000 to Io,000 catalog cards, the changing and refiling of nearly 4000 shelf-list cards, and the actual handling of the volumes. This last step covered verification of the books with the cards, frequent recataloging of the books, fitting the books into the new classification scheme, and penciled marking of the books with the new numbers which the bindery department would eventually place on the spines.

\section{Chief Problems}

All of these processes constituted mere routine practice and there was adequate typing help. Nevertheless, the chief reason why it took two people more than two years to complete this job lies in the fact that there was so much trouble in locating the books, large numbers of which were not in their proper places on the shelves. The following constitute some explanations for their absence; explanations which are likely to account for the absence from the shelves of books today :

I. Many volumes were charged out to readers when first sought.

2. Many volumes were on reserve and in use in some departmental library.

3. Professors on sabbatical leave had carried off a few volumes.

4. A number of volumes were at an outside bindery.

5. Volumes that were reported missing on first search kept turning up in other sections of the stacks where inventory was going on.

6. Some books that were at first reported missing would later appear mysteriously in their right places.

7. Since Columbia is in a metropolitan district, with borrowers carrying books daily on subways, trolleys, etc., a few volumes that were reported lost and paid for, were discovered later in another library or in some bookshop.

\section{Gained from Interviews and Visits}

The second and third sources of information for this study may be handled together. Through these visits and interviews, which have been frequent and have extended over a period of a good many years, it has been possible to gain familiarity with reclassification methods in many different types and sizes of library. Nearly always I have jotted down the findings on the spot or have written up the results at the end of the day. The following are some conclusions that have been drawn from these notes:

I. Reclassification is a slow process, even in a relatively small library, because recataloging is usually required for a good percentage of the books involved.

2. Reclassification for a closed shelf library seldom seems worth while; for an open shelf library it is frequently helpful for both readers and staff.

3. The hiring of extra help for a reclassification project should be carefully considered from every angle. Even an experienced classifier who comes from the outside will need considerable time to orientate himself in regard to the particular needs of an individual library. The larger the library, the longer will be the time of adjustment.

4. Because of the cost, time, and frequent interference with readers and staff, reclassification should never be embarked upon unless the library is quite sure that the existing system of classification seems to be impeding the progress of the library's service.

5. A system of classification that seems ideal for one library will not necessarily meet the needs of another institution. Care- 
ful investigation of various systems and their applications in several libraries is necessary. The best possible system must be adopted now, or all the difficulties of another reclassification may have to be experienced again in a few years.

6. In college and university libraries there seems to be no reason why special and departmental collections, if housed in separate rooms or buildings, cannot be classified according to systems which are different from the scheme adopted for the bulk of the general collection.

\section{Gained from Existing Literature}

So far as can be ascertained, no entire book has as yet been devoted to the subject. It happens that I have been in touch for several months with someone who is preparing an exhaustive study of the problem, the results of which, if published, may constitute a fair-sized book. The librarian undertaking this investigation is Mr. Maurice Tauber, an experienced classifier, who is at present a student at the Graduate Library School, Chicago University. Mr. Tauber's title is to be: "Reclassification and Recataloging of $\mathrm{Ma}$ terials in College and University Libraries." He has secured data from sixty-six libraries that have answered his questionnaire, so that his final presentation of facts should prove an authoritative guide to anyone interested in reclassification.

Material in print that is now available exists almost entirely in periodicals, since only scattered references can be discovered in general textbooks on cataloging and classification. A number of the best and most recent articles consist of addresses made at both the Large and Small Libraries Round Table meetings of the A.L.A. Catalog Section at the 1933 Chicago conference. ${ }^{2}$ Of these papers,

\footnotetext{
2 In the A.L.A. Proceedings of this conference may be found not only abridgements or digests of
}

that of Dr. Bishop might receive special mention because his remarks were mainly from the administrative angle. Slightly antedating these conference addresses is an article entitled: "What Price Reclassification?" by Elizabeth P. Jacobs and Robinson Spencer. This appeared in the Catalogers' and Classifiers' Yearbook, No. 3 , in 1932. It details the actual experiences of the reclassification project at the University of Rochester Library and includes statistics of cost, time, and personnel. After reading this account librarians contemplating reclassification should be able to figure more or less accurately the expenditure required.

\section{Questions Sent Twenty Selected Libraries}

Both because of lack of time and the fear of duplicating Mr. Tauber's work, I avoided the questionnaire method in acquiring facts from this source. Since my previous contacts with the subject had been mostly from the classifier's point of view, I decided to send out a few general, rather than technical, questions to the administrators of twenty college and university libraries. ${ }^{3}$ In order to make fairly certain that the institutions selected would have had a reclassification problem, recent numbers of the annual report of the librarian of Congress were consulted for libraries that were reported to be using the L.C. system of classification either for all or part of their collections. These lists were consulted merely for the purpose already stated, and not at all for the reason of finding out how well suited the L.C. classification was for the collection of any library. The twenty libraries selected were chosen purposely from dif-

all these addresses, but also an indication of the name and number of the periodical in which the majority of these papers were later printed in full. 3 A complete alphabetical list of the libraries circularized will be found at the end of this paper. 
ferent parts of the country. In order to include institutions of various sizes the latest number of the American Library Directory was consulted. Incidentally, since few small libraries have ever adopted the L.C. classification system, the majority of the institutions written to were those which would be said to have large collections. While the size range was from about 50,000 to $4,000,000$ volumes, only six of the twenty collections were under 200,000 volumes. A letter containing the four following questions was sent:

I. Has your adoption of the L.C. classification been for the whole library or only for one or more of your special collections or departments?

2. If your adoption of this system has been only for one or more special collections or departments, do you find it a detriment to have the main body of your books classified according to another system?

3. Do you believe that the service to readers has been so improved by the change that the time, money, and general upheaval involved in reclassifying have been worth while?

4. Do you think that as satisfactory service could have been provided for readers if you had not reclassified according to another system but had merely expanded and modernized your original system?

Of the libraries circularized, nineteen, or 95 per cent, sent in replies. Only seventeen answers, however, were usable, since one arrived after the statistics for this paper had been completed, and another showed a misunderstanding on the part of the librarian in regard to the reason for circularizing his institution. Of the seventeen valid replies, thirteen were sent in by administrators, three by catalogers, and one by an assistant librarian.

\section{Replies Hard to Tabulate}

The returns from the first two questions will be handled together, in so far as the information relates to whether the libraries adopted the L.C. classification for the bulk of the collection or only for one or more special departments or collections. These replies were fairly difficult to tabulate because in many cases libraries reported that they had adopted the L.C. classification for the whole collection and then, either in the direct answer to the first question or elsewhere in the return, mentioned a few exceptions. In one case the exceptions were so numerous that it was suspected that they involved a larger number of volumes than was covered by the rule. Another complication resulted from the fact that whenever the subject of law was mentioned among exceptions, it had to be discounted because the Library of Congress has not as yet published its law schedule. In the final analysis, thirteen of the seventeen libraries reported that the L.C. classification had been adopted for most of the collection; while four of the institutions are using it only for one or more special collections. It must be added, however, that among the thirteen libraries reporting L.C. in use for the bulk of the collection, eight, or slightly more than 61.5 per cent, acknowledged using one or more other schemes for special departments or collections. An extract from the reply of one of these eight librarians may help to illustrate the point:

We have adopted the Library of Congress classification as basic for the entire library, but it is quite possible that we may not use it for medicine and for forestry. In fact, in forestry we have combined one or two independent classifications with the L.C. scheme. . . A As for medicine, we are not yet decided. As a matter of fact, at least three-quarters of our medical library, which is quite extensive, is composed of bound files of journals and transactions of 
societies which are arranged in a single alphabet. The classification problem, therefore, concerns only a fraction of our holdings in the field of medicine.

The second half of the second question was apparently inaccurately worded. The information desired was whether or not it had proved a detriment when departmental or special collections were classified according to another system than that used for the main body of the collection. Seven of the seventeen libraries interpreted this question as referring to the as yet unclassified portion of their main book collections by the L.C. classification. Six of the seven confessed to some trouble in shelving, filing, the maintenance of both an old and a new catalog, etc. In most instances, however, the reply stated that readers and staff had already benefited so much from the change that they were willing to have suffered some inconvenience. The seventh library reported that a slight amount of trouble had arisen because of the fact that in reclassifying, the catalog had been changed from a classified to a dictionary arrangement.

Three libraries suggested that the problem did not apply to them, as their collections had been entirely reclassified according to the L.C. system.

\section{One Library Uses Nearly 80 Different Systems}

The remaining seven libraries were all institutions that had acknowledged the use of some other system of classification for departmental or special collections than that employed for the main body of the books. All of the seven reported that no inconvenience had resulted from the use of more than one scheme of classification. Many different reasons were given for the statement. One answer that was emphatic about this point reported the use of nearly eighty different classification systems, with apparently no ill results. The librarian of an institution where only three special or departmental collections have been handled according to another system of classification, but where the main collection has not yet been entirely reclassified, made the following statement :

In our library at the present time I feel that people are greatly relieved when the classification of the books with which they have mostly to deal has been finished. But here again the difficulties are chiefly in the process of reclassification and not in the practical handling of books in two or more systems.

The third question, which concerned itself with whether reclassification had been worth while, called forth the longest answers. In the final analysis, thirteen of the seventeen libraries considered that reclassifying had been worth while, two replied in the negative, and two were in doubt. Many of the thirteen institutions that rendered a favorable reply stressed the recataloging that had gone on along with the reclassification. As one librarian put it: "Since recataloging was called for in any case, reclassification did not involve much extra confusion. Service to readers undoubtedly has been improved by recataloging and reclassification; how much of the improvement is due to reclassification alone, it would be difficult to say." Another library remarked: " $U_{p}$ to the present time the expense of reclassification may not seem to be justified by the results, but in the long run we expect to gain by the change." A rather unusual reaction was received from one institution where reclassification has been going on for over twenty years: "We believe that 
reclassification can be so organized that a so-called 'general upheaval' is not necessary." It seems certain that many administrators would like to find out the secret of how this institution has handled its various problems.

\section{Do Not Recommend Expansion of Old System}

Of the seventeen valid returns from the fourth question, eleven indicated that as satisfactory service could not have been provided for readers if the old system of classification had been expanded and modernized. Three librarians thought that just as satisfactory service would have resulted if changes had been made in the old system, and two were in doubt about the matter. One reply could not be tabulated under any of these headings, since this library is using L.C. only in one departmental collection. While the change to the L.C. system has been beneficial in the case of this isolated department, the librarian reports that, on the whole, the library administration is opposed to reclassification except under unusual circumstances. He added: "We feel that the time and money spent in reclassifying is rarely worth while. The new classification usually proves within the course of years to be far from perfect and we think that the money could be spent in better ways."

Besides sending answers to the four questions, many libraries tucked in other information in the returns; others accompanied the formal reply with a letter that discussed further points. Two of these points, since they were emphasized again and again, deserve special consideration. Ten replies included reasons why the libraries were glad that they had adopted the L.C. system in reclassifying. The reasons were various, but perhaps the remark most worthy of quotation was: “. . . the L.C. classification is far better than anything we could have made out of our original system, and is probably better than any one person or small group of persons could make, for the L.C. must have had experts in each field." The other point relates to reclassification in open and closed shelf libraries. Most of the letters that included reference to the matter stressed the fact that the stacks were open only to graduate students and the faculty. More than one library of this type mentioned that reclassification was especially hard on the pages who are sent to look for books. Possibly Mr. Tauber's study may reveal some interesting facts about open shelf libraries and reclassification.

\section{Conclusion}

A final summing up of the findings from the answers received and of the information gained from other sources might be reduced to the following statements. The reclassification of college and university libraries is a major undertaking. It is much easier, and often it proves quite as profitable, to make changes only for special collections or departments. When, however, the bulk of a collection has been reclassified because of the general inadequacy of an old classification system, the results have usually justified the means. Because libraries differ so widely in many respects, each institution must make a thorough study of its own situation, in addition to a study of how the problem has been handled in other places. In no case does it seem wise to adopt the slogan: "It is the fashion to reclassify, and we wish to be in the mode."

(Continued on page 175) 
judgment but if he is competent to select he should also be granted competence to reject material. Although this solution provides no specific formula whereby propaganda can be automatically tested, admitted or rejected, it would seem that fundamentally usefulness could be accepted as the first principle for admission. With this as a guide all three types of propaganda ; namely, "good," "innocuous," and "harmful" would be admitted in proportion to their usefulness in any given type of library. Regardless of policy the first two types need cause little concern. As far as the third, or "harmful," type is concerned it would seem our function might go beyond education or censorship, even beyond any treatment which may be devised for the actual handling of this material.

\section{No Immediate Cause for Alarm}

It is still generally agreed that "it can't happen here." As long as this condition exists there is no particular cause for alarm over the subversive effect of propaganda in our college, university, and reference libraries for two reasons. First, we are dealing to a certain extent with an enlightened clientele and one which has been more or less exposed to some "education" with regard to propaganda. Second, propaganda to succeed must have a fertile ground. As long as we are a moderately prosperous, confident, and reasonably well satisfied people we are not apt to fall prey to political or economic "isms." So, it would seem that in troublous times like these it behooves us to look beyond the actual treatment accorded propaganda; to look, rather, toward the possibility of aiding in the solution of the problems which now give rise to propaganda, to be keenly aware of the changes taking place in our political, economic, and social life and, at the first sign of danger to the system which has given rise to libraries and freedom of thought and expression on an unprecedented scale we should be ready to adopt vigorous counter measures. Amidst all this we must remember that values change and we cannot put ourselves in the position of being unalterably opposed to change. All this will require a keen mind and a deep understanding of humanity, but the challenge and the prize are worthy.

\section{Reclassification of College and University Libraries}

(Continued from page ${ }_{16} 6_{4}$ )

\section{Libraries That Cooperated in the Study}

Brown University, Providence

Catholic University of America, Washington

Colby College, Waterville, Me.

College of Saint Catherine, Saint Paul

Cornell University, Ithaca, N.Y.

Harvard University, Cambridge, Mass.

Haverford College, Haverford, Pa.
Iowa State College, Ames

Johns Hopkins University, Baltimore

New York University, New York

Ohio State University, Columbus

Stanford University, Calif.

Swarthmore College, $\mathrm{Pa}$.

Temple University, Philadelphia

University of California, Berkeley

University of Cincinnati, Cincinnati

University of Michigan, Ann Arbor 